
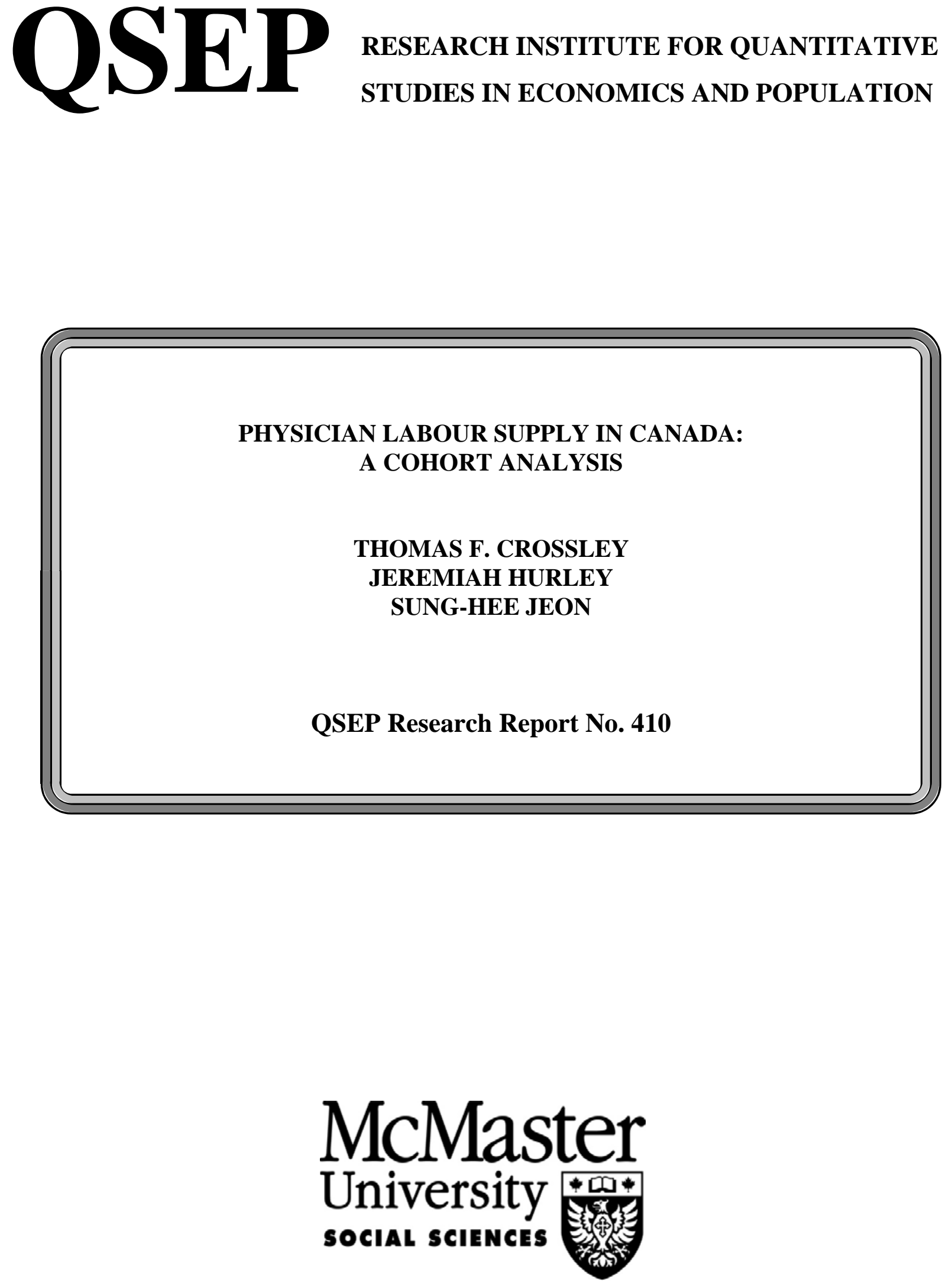
PHYSICIAN LABOUR SUPPLY IN CANADA:

A COHORT ANALYSIS

THOMAS F. CROSSLEY

JEREMIAH HURLEY

SUNG-HEE JEON

QSEP Research Report No. 410

September 2006

Thomas F. Crossley is a QSEP Research Associate and a faculty member in the McMaster University Department of Economics. Jeremiah Hurley is a faculty member of the Department of Economics at McMaster University and a member of CHEPA. Sung-Hee Jeon is a research fellow with the Melbourne Institute of Applied Economic and Social Research, University of Melbourne.

This report is cross-listed as No. 162 in the McMaster University SEDAP Research Paper Series.

The Research Institute for Quantitative Studies in Economics and Population (QSEP) is an interdisciplinary institute established at McMaster University to encourage and facilitate theoretical and empirical studies in economics, population, and related fields. For further information about QSEP visit our web site http://socserv.mcmaster.ca/qsep or contact Secretary, QSEP Research Institute, Kenneth Taylor Hall, Room 426, McMaster University, Hamilton, Ontario, Canada, L8S 4M4, FAX: 905521 8232, Email: qsep@mcmaster.ca. The Research Report series provides a vehicle for distributing the results of studies undertaken by QSEP associates. Authors take full responsibility for all expressions of opinion. 


\title{
Physician Labour Supply in Canada: a Cohort Analysis
}

\author{
September $28^{\text {th }}, 2006$ \\ Thomas F. Crossley \\ Faculty of Economics, University of Cambridge \\ and \\ Department of Economics, McMaster University \\ Jeremiah Hurley \\ Department of Economics and Centre for Health Economics and Policy Analysis, McMaster University \\ Sung-Hee Jeon \\ Department of Economics, McMaster University \\ and \\ Melbourne Institute of Applied Economic and Social Research, The University of Melbourne
}

Author order is alphabetical, and the authors made equal contributions to the work. We would like to thank Brian Hutchison and Philip DeCicca, McMaster University, David Green, University of British Columbia, and Owen Adams and Lynda Buske, Canadian Medical Association for valuable comments, as well as Shelley Martin, Canadian Medical Association, for assistance with the data. We also acknowledge financial support from the Canadian Institutes Health Research and the Social and Economic Dimensions of an Aging Population (SEDAP) Research Program at McMaster University. We also acknowledge funding provided to the Centre for Health Economics and Policy Analysis by the Ontario Ministry of Health and Long-term Care. The views expressed in this paper do not represent the views of the Canadian Medical Association or of the Ontario Ministry of Health and Long-term Care.

Corresponding Author: Thomas Crossley, Faculty of Economics, University of Cambridge, Austin Robinson Building, Sidgwick Avenue, Cambridge CD3 9DD, UK, phone: +44 (0) 1223 335225, fax: +44 (0) 1223 335475, email: Thomas.Crossley@econ.cam.ac.uk. 


\title{
Physician Labour Supply in Canada: a Cohort Analysis
}

\author{
Thomas F. Crossley, Jeremiah Hurley, Sung-Hee Jeon
}

\begin{abstract}
:
This paper employs cohort analysis to examine the relative importance of different factors in explaining changes in the number of hours spent in direct patient care by Canadian general/ family practitioners (GP/FPs) over the period 1982 to 2002. Cohorts are defined by year of graduation from medical school. The results for male GP/FPs indicate that: there is little age effect on hours of direct patient care, especially among physicians aged 35 to 55; there is no strong cohort effect on hours of direct patient care; but there is a secular decline in hours of direct patient care over the period. The results for female GP/FPs indicate that: female physicians on average work fewer hours than male physicians; there is a clear age effect on hours of direct patient care; there is no strong cohort effect; there has been little secular change in average hours of direct patient care. The changing behaviour of male GP/FPs accounted for a greater proportion of the overall decline in hours of direct patient care from the 80's through the mid 90's than did the growing proportion of female GP/FPs in the physician stock.
\end{abstract}

Keywords: Physician; Labour Supply; Hours; Cohorts

JEL Classifications: I11; J24 


\section{Introduction}

This study investigates changes over the last two decades in the hours Canadian general/ family practitioners (GP/FPs) spent providing direct patient care. The analysis follows national cohorts (defined by year of graduation from medical school) of Canadian GPs/FPs over the period 1982-2003 to examine factors underlying changes in physicians' average hours of direct patient care. The findings challenge some commonly held ideas regarding the factors driving changes in physician labour supply over this period.

Changed physician labour supply has recently taken on increased importance. The 1990s saw the development of a shortage of physicians and impaired access to physician services for many Canadians. Physician shortages have always existed in rural and remote areas and in particular physicians specialties, but the current overall shortage of family physicians, even in relatively large towns and small cities, is unprecedented. The speed with which the shortage has arisen is even more surprising: in less than a decade, the supply of physicians in Canada reversed from a perceived surplus of physicians to a perceived shortage (Fooks et al. 2002; Chan 2002).

The shortage has largely been attributed to changes in physician supply at the extensive margin, i.e., the numbers of physicians. The decision by many provinces to reduce medical school enrolments is perhaps the most often-cited cause (Canadian Medical Forum Task Force 1999, Fooks et al. 2002). Chan (2002) demonstrated that the impact of reduced medical school enrolment on physician supply is

only a small part of the story. Quantitatively, changed training requirements, reduced intake of foreign medical graduates and retirements were more important than reduced medical school intake. Perhaps the most surprising aspect of Chan's analysis is that, after adjusting both for the changing age-structure of the population and the changing age-sex composition of the physician workforce, the number of physicians per capita in Canada fell only 5\% between 1993 and 2000, the period during which the shortage emerged. 
This raises questions as to what was happening to the intensive margin --- the amount of direct patient care by the existing stock of practicing physicians. Indeed, recent evidence suggests that, just about the time that concern about a surplus of physicians peaked (in the mid-to-late 1980s), physician labour supply began to change. In 2003, for instance, physicians under the age of 45 spent 20\% less time providing direct patient care than they did in 1982 (Buske 2004). Census data documents that although physicians still work more hours than other professionals in Canada, they decreased their average total weekly hours of work by five hours between 1981 and 2001 (Table 1). Over the same period, the average weekly working hours of all other professionals except veterinarians either remained unchanged or increased. A 2001 National Family Physician Workforce Survey revealed that a greater percentage of Canadian family doctors reduced their work hours between 1999 and 2001 than increased them, and the large majority of them planned further reductions in their work hours between 2001 and 2003 (CFPC, 2002). Similarly, in Ontario 20\% of family physicians reduced their work hours between 1999 and 2001, $19 \%$ planned to reduce their work hours in the subsequent two years, and only $3 \%$ expressed an intention to increase their work hours.

These trends partly reflect demographic changes in the stock of practicing physicians that don't necessarily imply structural changes in underlying behaviour. For instance, female physicians, who work fewer hours on average than male physicians, make up a rapidly increasing proportion of practicing physicians. Physicians are also older on average, and physicians over age 65 historically work fewer hours on average than younger physicians. The trends, however, likely also reflect in part responses changes in the practice environment for physicians, such as changed levels of and regulations of physician fees. Finally, some have argued that the preferences and personal constraints of today’s younger physicians differ from historical norms. Physicians increasingly have professional spouses with full-time careers and, in particular, a young physician today is more likely to marry another physician than was the case in the past (Buske 2005). This both creates a distinct set of family time constraints compared to 
earlier periods when physicians were more often the sole source of household income and creates a source of large non-practice household income, which the literature suggests will decrease physician labour supply.

Understanding the relative importance of these (and other) factors potentially driving the reduction in physicians' average hours of work is essential for developing effective policies to address physician shortages and problems of access to physician services. Our study seeks to provide insight into the relative roles of changing physician demographics, cohort differences and general time effects in explaining changes in weekly physician hours of direct patient care over the last 20 years. This study, which utilizes repeated cross-section data from the Canadian Medical Association Physician Resource Questionnaire Survey as a quasi-panel, is among the first to study changes in physician labour supply over an extended period of time. The quasi-panel nature of the data provides us with two dimensions of variation - across cohorts and through time - which provides much greater scope for understanding changes in physician behaviour than either cross-section or aggregate time-series data. The key idea is that many explanations for changes in FP/GP labour supply can be interpreted either as an age effect, a cohort effect or a time effect. Thus disentangling age, cohort and time effects can help us to discriminate between different hypotheses. For example, our findings indicate that reductions in hours of direct care occur across nearly the full age distribution of physicians. This is inconsistent with explanations that focus on behaviour specific to younger cohorts of physicians (a cohort effect), and suggests more fundamental changes in the practice environment that affected physician behaviour across a wide range of cohorts and ages (a time effect).

In the next Section we briefly review the empirical literature on physician labour supply, Sections 3 and 4 describe our data and research methods respectively; Section 5 presents our results; Finally, Section 6 provides a concluding discussion. 


\section{Physician Labour Supply: The Empirical Literature}

Empirical evidence about how physician labour supply varies according to physician characteristics or to the policy environment is surprisingly limited. A large descriptive literature documents how hours of work vary according to a number of demographic characteristics of physicians, both in Canada and internationally, while a much smaller literature draws on labour economics to estimate physician labour-supply functions.

The descriptive literature most commonly investigates the relationship between hours of work and a physician's age and sex. The interest in these characteristics derives from the substantial changes in the age-sex distribution of the physician stock noted above. The proportion of practicing physicians in Canada who are women has quadrupled since the 1950s: in 1961, 7\% of physicians were women; in 2000 this proportion had risen to 28\% (CMA 2001). The average age of physicians in Canada, as for the whole population, has been rising steadily over the past two decades. The proportion of physicians aged 65 and over rose from $7.0 \%$ in 1981 to $11 \%$ in 2000 (Chan 2002). These trends would be of little consequence except that it is well-documented that female physicians work fewer hours on average than male physicians and practice less intensively (as measured by services per hour) (Chan 2002, CFPC 2002, A Physician Human Resource Strategy for Canada 2003, Cohen et al. 1991) and that older physicians, especially those over age 65, work fewer hours than do other physicians (Martin 2002; Slade and Busing 2002; Chan 2002). Female physicians, for example, worked an average of 49.1 hours per week compared to 56.0 hours per week for male physicians ${ }^{1}$ (Martin 2002) and provide one-quarter to one-third fewer services than male physicians (Woodward and Hurley 1995, Chan 2002). Not surprisingly, the gender differential varies over the life-cycle: it is smallest at age 25-29 and greatest during the child-rearing ages of 35-44. Female physicians are more likely to work part-time, work in group practices, bill during fewer months of the year, earn less, and see fewer patients (Cohen et al. 1991, Boerma and van den Brink-

\footnotetext{
${ }^{1}$ This excludes on-call responsibilities.
} 
Muinen 2000). However, statistical differences between male and female physicians diminish substantially after controlling for part-time work. These Canadian patterns are consistent with international patterns. Females physicians across Australia, Canada, England, and the United States are more likely to practice in urban settings and work 7 to 11 fewer hours per week than do male physicians (McMurray et al. 2002).

Turning to estimates of labour supply functions, early studies (e.g., Feldstein (1970), Brown and Lapan (1979), Hu and Yang (1988) and Brown (1989)) all found evidence of a backward-bending physician labour supply curve. The results of more recent studies are mixed. Thornton (1998) and Rizzo and Blumenthal (1994) found a positive relationship between fees and physician labour supply. Rizzo and Blumenthal (1994), using physician experience as an instrument for earnings, estimate a typical income-leisure choice model for young physicians. The estimated (uncompensated) wage elasticity for young male physicians is 0.23 . Female physicians, with an imputed elasticity of 0.49 , appear even more responsive to changes in wages than males. Thornton and Eakin (1997) found evidence of a backward bending labour supply curve, but because fee increases led physicians to employ more medical supplies and auxiliary services while working fewer hours, the overall supply of services actually increased while physician labour supply decreased. Both Rizzo and Blumenthal (1994) and Thorton and Eakin (1997) found evidence of a substantial negative non-wage income effect on labour supply for both male and female physicians. ${ }^{2}$

A recent Canadian study of physician labour supply, Ferrall et al. (1998), used survey data from the 1990 CMA Physician Resource Questionnaire and found that, controlling for practice setting, physicians paid primarily by fee-for-service work 5.5 fewer hours per week in total than those paid primarily by salary. However, fee-for-service physicians see patients for 5.9 more hours each week than

\footnotetext{
${ }^{2}$ Hourly wages are measured as the net practice income earned by the physician divided by the annual numbers of hours spent in patient care. The non-practice income variables were spousal income and the physician's educational indebtedness at the time of graduation from medical school.
} 
the salaried physicians. They also found important differences across provinces in patient contact hours (e.g., contact hours in Manitoba and Quebec differ by 8.9 hours per week) and suggest that these crossprovince differences are due to differences in how physician fees are set.

Because almost all of these estimates are based on cross-sectional data, they can provide only limited insight into why the physician labour supply has changed over the last two decades. The goal of our research, therefore, is to examine changes over time and differences across cohorts in physician time spent in direct patient care.

\section{Data}

\subsection{The Canadian Medial Association’ Physician Resource Questionnaire}

The Canadian Medical Association regularly conducts national physician surveys of both members and non-members of medical associations about physician workforce issues. The Physician Resource Questionnaire (PRQ) surveyed physicians in 1982, 1986, 1990, 1993, 1995, 1997, 1998, 1999, 2000, 2001, 2002 and 2003. The PRQ for 1982, 1986 and 1990 were censuses of all physicians licensed to practice medicine in Canada. Beginning in 1993, the PRQ surveyed a random sample of physicians. The PRQ contains the only consistently defined Canadian data available for an extended time period regarding hours of professional activities by physicians. The PRQ contains demographic information (e.g., year of birth, year of graduation, specialty, gender and practice location), average number of hours worked per week, remuneration modes and practice setting. Over 1982-2003, the PRQ has asked consistently defined questions regarding weekly hours of work in various professional activities. ${ }^{3}$ The survey questions related to labour supply are presented in Appendix A.

\footnotetext{
${ }^{3}$ PRQ is self-reported survey data, and therefore, may be subject to recall error. Jeon and Hurley (2004) compare self-reported hours of direct patient care and fee-for-service billing for a random sample of Ontario GP/FPs in 1990. This analysis indicates that self-reported hours correlate with the billings data.
} 


\subsection{Analysis Sample}

The analysis focuses on general and family practitioners (GP/FPs). We do this for both pragmatic and policy reasons. From a pragmatic perspective, GP/FPs are the largest specialty grouping of physicians, ensuring sufficient sample size for our study. We perform separate analyses by gender because of different patterns of labour supply in males and females. From a policy perspective, the overall shortage and compromised access to GP/FPs services that emerged during the 1990s was a new phenomenon in the recent history of the Canadian health care system. Because GP/FPs are the key primary care providers in the Canadian system, compromised access to GP/FPs raises particularly difficult policy issues.

We selected GP/FPs under 65 years of age whose major professional activity is direct patient care. We excluded physicians in postgraduate medical training (interns and residents). ${ }^{4}$ The sample was then symmetrically trimmed by dropping the upper and lower $1 \%$ of each of males and females by year to eliminate outliers with respect to hours of work. ${ }^{5}$ Our final sample sizes include 45,362 observations in total, of whom 34,282 are male; 36,902 practice in urban areas; 17,637 work in solo practice.

We then created five cohorts for each gender according to the year of graduation from medical school as follows: Cohort 1 graduated prior to 1960; Cohort 2 during to 1960s; Cohort 3 during to 1970s; Cohort 4 during to 1980s; Cohort 5 during to 1990s. The sample sizes of the cohorts are: 6143 before 1960; 9444 during 1960s; 19,328 during the 1970’s; 9097 during the 1980’s; and 1350 during the 1990’s. Table 2 shows the number of observations by year and gender of physician. To ensure reliable estimates we employ only year-cohort cells with at least 35 observations in our analysis; this eliminates a small number of observations at older ages.

\footnotetext{
${ }^{4}$ Until the early 90's, physicians were allowed to enter practice as general practitioners after one year of postgraduate training; a two-year family medicine residency became the prerequisite for primary care practice in 1993.

${ }^{5}$ This trimming eliminated observations with less than 4 hours of direct patient care or more than 80 hours of direct patient care.
} 
Our data reflect well-known demographic changes in the physician stock. Figure 1 shows that the proportion of female physicians in the stock of physicians has more than doubled during the time period of our study. Figure 2 compares the average age of male and female physicians by year. The average age of male physicians has increased by 8 years over two decades and, as expected the average age of female physicians is considerably less than that of male physicians.

In our sample of GP/FP, average reported hours of direct patient care fell from 45.4 hours per week in 1982 to 38.3 hours in 2003, a drop of just over 7 hours, or almost 16 percent. Average hours of direct patient care reported by male GP/FPs fell by 12 percent (5.6 hours from a starting point of just over 47 hours per week); for female GP/FPs the fall in average hours per week was 9 percent (3.4 hours from a starting point of just less than 37 hours per week.) The overall drop exceeds the drop in either gender because of the composition effect of an increasing fraction of female GP/FPs. These numbers strongly suggest that the changes on the intensive labour supply margin had a great deal to with the shortage of GP/FP services that emerged in the 1990s. We now turn to a more detailed analysis of these changes.

\section{Methods}

We employ cohort methods to examine changes in the labour supply of Canadian GP/FPs over the period 1982-2003. While cohort methods have been used to examine labour supply in Canada more generally (for example, Beaudry and Lemieux, 1999), they have not, to our knowledge, been applied to the study of physician labour supply. The central principle of this method is that cohorts can be tracked over time using a series of repeated cross-section data (quasi-panel data) in a manner analogous to the way individuals can be followed in true panel data. ${ }^{6}$ Specifically, we investigate the part played by the

\footnotetext{
${ }^{6}$ This is true as long as the composition of cohorts does not change over time. The most important source of composition changes, especially among the earliest graduation cohorts, is retirement. Hence, as noted above, we exclude physicians aged 65 and over from our sample. In addition, incoming international medical graduates or returning Canadian physicians, as well as the emigration of Canadian physicians from Canada, can also cause changes to the composition of graduation cohorts over the study period. The PRQ data suggest a moderate decrease over the study period in the proportion of physicians who are foreign medical graduates (a decrease from approximately $25 \%$ to $20 \%$ ) There was a decline in
} 
changing age distribution of physicians, differences between successive graduating cohorts ("cohort effects”) and time (year) effects in explaining the reduction in physician hours of direct patient care since 1982. The quasi-panel nature of the data provides us with two dimensions of variation - across cohorts and through time, and allows us to test alternative explanations for the change in average hours of direct patient care.

There is a well-known identification problem in cohort studies (see for example Deaton, 1997). The two dimensions of variation do not allow for separate, formal identification of arbitrary age, time and cohort effects. This follows from the exact linear relationship between these quantities and is directly analogous to the impossibility of separating age and cohort effects in a single cross-section of data. Although we define cohorts by year of graduation (from medical school) rather than year of birth, these two quantities are highly correlated so that the usual identification problem applies. (And in some cases we examine years of practice experience, rather than age, in which case the linear dependency holds exactly).

Nevertheless, parsimony sometimes points strongly to a particular interpretation of the data and we shall make use of this below. In addition, with two dimensions of the data, it is possible to test onedimensional explanations of observed patterns (for example, the hypothesis that common time effects capture all of the salient features of the data) and we make use of this fact as well.

All of our analysis is conducted separately for men and women. This allows us to identify the effect of the changing gender composition of the physician workforce.

international medical graduates entering Canada after the mid to late 1990s as a result of the restrictions on the number of visa postgraduate trainee positions funded by Ministries of Health Canada by1993/94. The important question in our context is when these international medical graduates immigrated to Canada. If international graduates move to Canada shortly after graduation, they will have a minimal effect on the changes in composition in their cohorts as defined by graduation year. This is likely the case for many, as they come to Canada for post-graduate training. In addition, the incentive is for a physician to enter Canada early in their career because they are required to do further training in order to practice in Canada. 
We begin by examining physician hours of direct patient care using three types of profiles: 1) cross-sectional age profiles; 2) cohort-specific year profiles; 3) cohort-specific age (or years of practice) profiles. We first examine cross-sectional age profiles that plot, for each study year, the average hours of direct patient care by physician age. An age profile from a single annual cross-section confounds the age effects with generational, or cohort, differences. Younger and older people belong to different cohorts, so that if there are true cohort effects, a cross-sectional age profile will differ from the life-cycle age profile of any cohort. We then examine cohort-specific year profiles, which depict, for each study year, the average hours of direct patient care among physicians in different cohorts. These profiles compare how the hours of direct patient care in different graduation cohorts evolve over time. Because each cohort ages over time, these profiles confound age and time effects. Finally, we examine cohort-specific age and experience profiles which depict, at each age (or years of experience), the average hours of direct patient care. Again, because time passes as each cohort ages (or accumulates experience) these profiles confound age and time effects.

\section{Results}

\subsection{Male FP/GPs}

Figure 3 presents the age, year and cohort patterns in relation to hours of direct patient care among male physicians. Figure 3(a) shows four cross-sectional age profiles of hours of direct patient care in the years 1986, 1990, 1995 and 2000. Each line indicates the average hours of direct patient care worked by male physicians of that age during the indicated year. ${ }^{7}$ A comparison of the lines for the different years reveals that average hours of patient care fell through time among all ages, although the 1995 and the 2000 age profiles almost coincide. A comparison across ages (and hence cohorts) within a

\footnotetext{
${ }^{7}$ We present only these four years to maintain the clarity of the figure, although other survey years exhibit the same pattern The age profiles are also smoothed by calculating average hour of direct patient care at 3-year intervals (with the center of each interval and the corresponding average marked by dots in the Figure).
} 
year profile indicates that hours of patient care remain fairly constant from age 30 to age 55 and decline thereafter. This age pattern is consistent across all years.

We can see the effect of the time (year) on hours of direct patient care more clearly in Figure 3(b), which indicates the average hours of direct patient care by male physicians in each cohort during each survey year. The shapes of the year profiles are similar for all cohorts. From the early 1980s through 1995, the average hours of direct patient care decreased for all cohorts of physicians. From the late 1990's through the early 2000's, the year profiles are essentially flat. The profiles also reflect previously noted absence of cross-sectional age effects. In 1982 there is effectively no difference in hours of direct patient care among the first, second and third cohorts, whose average ages are 55, 41 and 32 respectively. In fact, the year profiles of cohorts who graduated in the 50's, 60's, 70's, 80's and 90's all overlap.

How can we interpret these Figures? The simplest interpretation of these figures is that there are no significant age or cohort effects in hours of direct patient care among male GP/FPs. Under that interpretation, the flat cross-sectional age profiles in Figure 3(a) reflect the fact that the true (life-cycle) age profile is flat (at least until age 55 or 60), and there are no cohort effects to cause the cross-sectional age-profile to deviate from the true age profile. The shifting down of cross-sectional age profiles through time represents common time effects. Similarly, absent age and cohort effects, each cohort would provide the same (average) hours of direct patient care at a given point in time. This is exactly what we see in Figure 3(b). The decline hours between 1982 and 1995 that appears to be common to all cohorts is then interpreted as a series of common time effects.

The identification problem described in Section 4 means that, formally, there are alternative combinations of age, cohort, and time effects that explain the data equally well. However, alternative explanations are much less parsimonious. For example, the flat cross-sectional age profiles could result from a combination of age effects and exactly off-setting cohort effects. However, it strains credulity to 
believe that cohorts are significantly different but that the rate of change in behaviour across cohorts over the last 20 years has been constant, and exactly offset the effect of aging on hours of care.

Figure 3(c) presents cohort-specific age profiles, which plot the average hours of direct patient care by physicians in each cohort at the indicated ages. Figure 3(d) does the same with respect to physician's years of practice. Although not everyone graduated from medical school at the same age, age and years in practice are highly correlated, so the two sets of cohort profiles are very similar. The shape of each line seems to reflect a trend over time of decreasing hours of direct patient care. Given that we have interpreted Figures 3(a) and 3(b)) as an absence of age and cohort effects in hours of care, our interpretation of Figures 3(c) and 3(d) is that both the downward slope of the profiles and the vertical distances between cohort profiles reflect time, or year effects, not age or cohort effects. For example, the first point for Cohort 3 indicates that when physicians who graduated in the 70's were on average 32.5 years old (in 1982), they worked about 47 hours on average. Seven years later in 1990, when they were on average 40 years old, they worked on average only 44 hours. With no age effect, this decrease must reflect a time (year) effect. Analogously, starting again from the first point for cohort 3 in Figure 3(c), but now moving straight vertically down, the profile of Cohort 4 indicates that when physicians who graduated in the 80's were 32.5 years old (in 1990) they worked on average only 43 hours. In the absence of cohort effects, this difference of about four hours indicates the sum of year effects between 1982 and 1990. These two estimates of the common year effects between 1982 and 1990 are statistically indistinguishable; if these two distances reflected age and cohort effects respectively, it would be an unusual coincidence that they (and other such pairs) were equal in this way.

These vertical distances converge at older ages, which are more recent years. The exception is the oldest cohort, whose age profile is quite steep beyond age 55. Of course, for this cohort, those ages are observed quite early in our data period. Thus these Figures, like Figure 3(b) suggest a decline in hours of 
care that was common to all ages and cohorts and was fairly continuous between 1982 and 1995 but decelerated, or perhaps even ceased, thereafter.

To summarize, we believe that a parsimonious interpretation of the data for male GP/FPs is that 1) there is little age effect, especially among male physicians aged between 35 and 55; 2) there is a secular decline (time trend) in hours of direct patient care, especially between 1982 and 1995; and, 3) there are no clear cohort differences in hours of direct patient care.

Because this is a one-factor interpretation of the data, and our data have two dimensions of variation, it is possible to test our interpretation. To do so, we regressed hours of direct patient care against a series of cohort and year dummies, under the assumption of no age effect on hours of direct patient care between 35 and 55. The year effects are jointly significant $(\mathrm{p}<0.000)$ and reflect a drop of 6 hours from 1982 to 1995, with no change thereafter. Cohort effects are not jointly significant ( $\mathrm{p}=0.37)$. Only the last cohort is marginally significant $(\mathrm{p}=0.09)$ working about 1.7 hours less than other cohorts. These results support our interpretation of the data. ${ }^{8}$

\subsection{Female FP/GPs}

Figure 4 presents the same analysis for female GP/FPs. Female physicians report fewer hours of direct patient care on average than do male physicians. For female physicians (unlike male physicians), age effects on hours of direct patient care appear to dominate all other effects. Figure 4(a) shows that, for each of the years included, the cross-sectional age-profiles are roughly u-shaped, with average hours of direct patient care declining up to about age 38 and then gradually rising with age. Though less pronounced, the cohort-specific year profiles in Figure 4(b) are consistent with this age effect. No strong time trends (year effects) are observed Figure 4(b), and the fact that the profiles overlap is most naturally interpreted as an absence of significant cohort effects among female physicians. Figure 4(c) and 4(d) show that the cohort profiles are closely bunched, again suggesting a dominant influence of age effects on

\footnotetext{
${ }^{8}$ The full regression results underlying these numbers are reported in Appendix B.
} 
hours of direct patient care. Childbearing and childcare are the most likely explanation for this pattern. To summarize, our interpretation of these data female GP/FPs is that: 1) females work fewer hours on average than males do; 2) there are clear age effects on hours of direct patient care; 3 ) the average hours of direct patient care for female GP/FPs show a remarkable stability across time and cohorts.

\subsection{Total hours of work}

Direct patient care is only one component of physician's work activity, so it is natural to ask whether the decline hours of direct patient care that we observe for male FP/GPs is associated with a decline in total hours of work, or instead, a reallocation of hours of work from direct patient care to other activities. The census data reported in Table 1 suggest that it is, at least in part, the former. Figures 5 and 6 explore this issue further. They compare cohort-specific year profiles of weekly total hours of work and the proportion of total hours spent in direct patient care for males and females respectively. In both male and female data, we observe a 'survey effect' resulting from the addition in 1997 of explicit survey prompts regarding the allocation of time across professional activities. However, the most dramatic decline in hours of direct patient care for male GP/FPs occurred prior to 1997. For male physicians both total hours of work and hours of direct patient care decreased through the 80’s and early 90’s. Overall there was no change in the proportion of total work hours spent in direct patient care. For female physicians there is no clear trend in total hours of work or in the proportional hours of direct patient care. These data suggest that the reduction of hours of direct patient care among male physicians did not result from a re-allocation of physicians’ work time among professional activities such as managing a practice, administration, research etc. Rather, it arose from a reduction in total hours of work.

\subsection{A Decomposition}

It appears that two of the most important drivers of the decline in the overall average hours of direct patient care among GP/FPs are the secular decrease in hours by male physicians and the increasing proportion of female physicians, who on average work provide fewer hours of such care. Although the 
latter has received considerable attention in policy debates, it is useful to estimate the relative importance of the two phenomena. This can be done through the following decomposition of the overall average hours of direct patient care:

$$
\begin{aligned}
& \text { Average hours in year } j=p_{m, j} \times h_{m, j}+p_{f, j} \times h_{f, j} \\
& =h_{f, j}+p_{m, j} \times\left(h_{m, j}-h_{f, j}\right)
\end{aligned}
$$

where, $p_{m, j}$ is percent of the physician stock that is male in year $j, p_{f}$ is the percentage that is female, $h_{m}$ is the average hours among males, and $h_{f}$ is the average hours among females.

We ask two questions. First, how much would the overall average hours of patient care among physicians have changed if males worked in 2002 the same hours as they did in 1982. This can be estimated as follow:

Average hours in year $j=h_{f, j}+p_{m, j} \times\left(h_{m, 1982}-h_{f, j}\right)$

Second, how much would the overall average hours of direct patient care have fallen if the proportion of females in the physician stock remained at the same level as in 1982:

$$
\text { Average hours in year } j=h_{m, j}+p_{f, 1982} \times\left(h_{f, j}-h_{m, j}\right)
$$

The decomposition results are presented in Figure 7. The lowest line (with circles) depicts actual overall average hours per week of direct patient care from years 1982 to 2003. It shows that, as noted in Section 2, average hours of direct patient care in our sample falls from 45.4 hours to 38.3 hours, a fall of 7.2 hours or almost 16 percent.

The middle line (with triangles) depicts what average hours would have been if there had been no change in the proportion of females between 1982 and 2003. In this first counterfactual, average hours per week average hours per week fall still by 5.2 hours to 40.3 in 2003. Thus the growing proportion of female GP/FPs can explain 2 hours out of a total drop of 7.2 hours. The top line (with squares) represents what average hours per week would have been if male physicians had maintained the same hours of direct 
patient care through the period as they did in 1982. When we hold the behaviour of male GP/FPs constant in this second counterfactual, average hours per week still fall by 3.9 hours to 41.5 hours per week in 2003. Thus changing behaviour among male GP/FPs can explain 3.3 hours out of an actual fall of 7.2 hours. The decomposition shows that the changing behaviour among male GP/FPs had a greater impact on the overall decline in hours of direct patient care than did the growing proportion of female GP/FPs in the physician stock.

\section{Discussion}

These findings have a number of implications for current policy debates regarding physician supply and access to physician services. First, the data reveal a significant change on the intensive margin of FP/GP labour supply with self-reported, average weekly hours of direct patient care per physician falling by almost 16 percent over the last 20 years. The current Canadian physician shortage, and the associated reduced access to physician services, are most often attributed to a change in the growth rate in physician numbers, particular associated with a reduction in medical school enrollments. However, our results, in conjunction with Chan's (2002) finding of relatively constant (adjusted) physician-population ratios, suggest that the intensive margin has been the far more important driver in the development of the current shortage. It is also likely the case that feasible routes out of the current situation involve adjustments on the intensive margin. This follows from the fact the that increasing hours of direct patient care by even $5 \%$ among the stock of practicing physicians will have greater short- and medium-run impacts on aggregate effective physician supply than even the large increases in medical school enrolments being implemented in many provinces.

Turning to the reasons for the observed changes on the intensive margin, our analysis of the PRQ data also casts serious doubt on a number of hypotheses that have been put forward in the policy debate. First, it is often suggested that a key factor in the current crisis is the behaviour of younger cohorts of physicians. It is supposed that their labour supply behaviour differs from the behaviour of older cohorts 
because of changes in family structures and labour force patterns (for example, the fact that physicians in younger cohorts are more likely to be married to another professional). However, we found no evidence in the data of significant cohort effects, and this would seem to undermine all cohort-based explanations of the current shortage. Instead, our results document a secular decline among all cohorts of male physicians, not just among younger physicians.

Second, it often supposed that the growing proportion of female physicians in the physician stock is responsible for the current shortage of physician services. Our analysis does confirm that female FP/GPs provide fewer hours of direct patient care, and that growing proportion of female FP/GPs can explain an important part of the decline in average hours of direct patient care. However, we find that that the secular decline in average hours of direct patient care among male physicians contributes a larger share of the total change. Of course, as this secular decline seems to have leveled off, and as women constitute a greater share of currently enrolled medical students than they do of the stock of physicians, it is possible that the growing proportion of female physicians may be a more important factor in the future.

Finally, it is not the case that the fall in direct patient care arose from a re-allocation of physician time among professional activities. Rather, it arose from a reduction in total hours of work.

Our finding that reductions in hours of direct care are driven by a secular decline (that is, a series of time effects) suggests that the explanation lies in some fundamental changes or change in the economic environment that affected physician behaviour across a wide range of cohorts and ages. Moreover, because labour-supply trends for physicians appear to differ importantly from those of other professionals, it is unlikely that general changes in the labour market or taxation can be responsible. This points future research towards specific changes in the physician labour market and practice environment (such as changes in remuneration and sources of non-practice income, and/or technological change in the practice of medicine and its impact on physician productivity.) 
One important caveat to this conclusion is the fact that the changes are concentrated only among male physicians. Nevertheless, the labour supply literature more broadly has long documented important gender differences in responses to changes in wages and unearned income. In the specific context analyzed in this paper, it is also worth noting that female FP/GP hours of direct patient care started (in 1982, the first year of our) from a lower base than their male counterparts (eg. Compare Figures 3b and 4b). Perhaps this accounts for the differential response.

A broader caveat to our entire analysis is that these data provide no direct insight into what has happened to the supply of physician services, which of course are the product of physician labour plus other practice inputs. Jeon and Hurley (2004), for example, document an inverse relationship crosssectionally between hours of work and services per hour. Evidence on trends in per-physician service supply is not consistent. Chan’s (2002) analysis suggests that per-physician service supply (as measured by billing levels) increased by 5\% for GP/FPs over the period 1989-1999, which he interpreted as a potential response to the growing physician shortage. However, in a detailed analysis of the practice patterns of GP/FPs in Winnipeg over the period 1991-2001, Watson et al. (2004) found that GP/FPs in Winnipeg aged 30-49 provided 20\% fewer visits in 2001 than their same-aged peers did in 1991; at the same time, FPs aged 60-69 actually provided one-third more visits in 2001 than the same-aged physicians did in 1991. These counter-acting effects led to a stable rate of visits per capita in Winnipeg over the period. While these analyses of service supply are not necessarily contradictory given the different samples and methods employed, they illustrate the need for more comprehensive analysis of trends in physician service supply.

Understanding the underlying causes of changes in physician labour supply is vital for developing sound health human resource policies. To best inform policy development, such analyses should place physician labour supply in a broader, and more structural, joint model of physician labour supply and service supply. The data requirements of such analyses would be very steep however, as they call for the 
marriage of labour supply data (such as we have analyzed here) with data on the prices and quantities of other inputs to, and outputs from, medical practice. Another promising strategy for future work would be to exploit provincial variation compensation and practice environment to help identify the importance of different factors in driving changes in physician behaviour. This also awaits better data. 


\section{References}

A Physician Human Resource Strategy for Canada (2003), Physician workforce in Canada: literature review and gap analysis. Ottawa: Canadian Labour and Business Centre.

Beaudry, P. and T. Lemieux (1999) "Evolution of the Female Labour Force Participation Rate in Canada, 1976-1994: A Cohort Analysis.” Canadian Business Economics. 7(2):57-70.

Boerma, W. and A. van den Brink-Muinen (2000). "Gender-related differences in the organization and provision of services among general practitioners in Europe.” Medical Care. 38(10): 93-1002.

Brown, D. and H. Lapan (1979), “The Supply of Physicians’ Services.” Economic Inquiry 17: 269-79.

Brown, M.C. (1989), “Empirical Determinants of Physician Incomes-Evidence from Canadian Data.” Empirical Economics. 14(4): 273-89.

Buske L. (2004), "Younger physicians providing less direct patient care” CMAJ, 170 (8): 1217.

Buske L. (2005), “Understanding the Physician Labour Market: Results of the 2004 National Physician Survey.” CERF Conference on Health Human Resource 2005.

Canadian Medical Association (2001) CMA Policy: Physician Resource Planning. Ottawa: Canadian Medical Association.

Canadian Medical Forum Task Force (1999). Task Force on Physician Supply in Canada. Ottawa.

Chan, B. (2002), From perceived surplus to perceived shortage: what happened to Canada's physician workforce in the 1990s? Ottawa: Canadian Institute for Health Information. 
Cohen, M., B.M. Ferrier, C.A. Woodward, C.H. Goldsmith (1991), “Gender differences in practice patterns of Ontario family physicians (McMaster medical graduates).” Journal of the American Medical Women's Association. 46(2): 49-54.

Deaton, A. 1997. Analysis of Household Surveys. Baltimore: Johns Hopkins University Press.

Feldstein, M. (1970), “The Rising Price of Physicians’ Services.” Review of Economics and Statistics. 52(2): 121-33.

Ferrall, C., A. Gregory and W. Tholl (1998), “Endogenous Work Hours and Practice Patterns of Canadian Physicians.” Canadian Journal of Economics. 31(1): 1-27.

Fooks, C., K. Duvalko, P. Baranek, L. Lamothe and K. Rondeau (2002b). Health Human Resource Planning in Canada: Physician and Nursing Work Force Issues. Canadian Policy Research Networks Inc. Ottawa.

Hu, T. and B. Yang (1988), “Demand for and Supply of Physician Services in the U.S.: A Disequilibrium Analysis.” Applied Economics. 20(8): 995-1006.

Jeon, S. and J. Hurley (2004), “The Relationship between Physician Labour Supply, Service Volume and Service Intensity” Working Paper 04-03, Centre for Health Economics and Policy Analysis, McMaster University, Hamilton.

Lapan, H. and D. Brown (1988), “Utility Maximization, Individual Production, and Market Equilibrium.” Southern Economic Journal 55: 374-89.

Martin, S. (2002), “More Hours, More Tired, More to Do: Results from the CMA’s 2002 Physician Resource Questionnaire.” CMAJ 167(5): 521. 
McMurray, J.E., M. Cohen, G. Angus, J. Harding, P. Gavel, J. Horvath, E. Paice, J. Schmittdiel and K. Grumbach (2002), “Women in medicine: a four-nation comparison.” Journal of the American Medical Women's Association. 57(4): 185-90.

Rizzo, J.A. and D. Blumenthal (1994), “Physician labor supply: Do income effects matter?” Journal of Health Economics. 13: 433-453.

Rizzo, J.A. and D. Blumenthal (1996), “Is the target income hypothesis an Economic Heresy?” Medical Care Research and Review. 53(3): 243-266.

Slade, S. and N. Busing (2002). "Weekly work hours and clinical activities of Canadian family physicians: results of the 1997/98 National Family Physician Survey of the College of Family Physicians of Canada.” CMAJ. 166 (11): 1407.

Thornton, J. (1998), “The labour supply behaviour of self-employed solo practice physicians.” Applied Economics, 30: 85-94.

Thornton, J. and B. K. Eakin. (1997), “The Utility-Maximizing Self-Employed Physician.” Journal of Human Resources. 32(1): 98-128.

Watson, D., A. Katz, R. Ried, B. Bogdanovic, N. Roos, and P. Happner. (2003), “Family Physician Workload and Access to Care in Winnipeg, 1991-2001. Canadian Medical Association Journal. Vol. 171(4): 339-342.

Woodward, C. and J. Hurley (1995), “Comparison of activity level and service intensity of male and female physicians in five fields of medicine in Ontario.” CMAJ. 153(8): 1097-1106. 
Table 1. Average Number of Hours Worked, by Selected Occupation, Canada, 1981-2001

Average number of hours worked in reference week among those working.

\begin{tabular}{l|cccccc}
\hline & \multicolumn{3}{|c}{ Year } & \multicolumn{2}{c}{ Change } \\
Occupation & 1981 & 1986 & 1991 & 1996 & 2001 & $1981-2001$ \\
\hline geologists & 41.89 & 40.68 & 41.21 & 42.73 & 42.38 & 0.49 \\
physicists & 42.42 & 42.37 & 40.12 & 42.65 & 41.19 & -1.23 \\
civil engineers & 41.31 & 41.45 & 41.30 & 42.01 & 42.69 & 1.38 \\
electrical engineers & 40.22 & 40.78 & 40.44 & 42.31 & 42.07 & 1.85 \\
mechanical engineers & 41.52 & 41.69 & 41.23 & 43.15 & 43.17 & 1.65 \\
economists & 39.58 & 40.41 & 39.54 & 40.47 & 40.22 & 0.64 \\
sec. school teachers & 36.80 & 37.79 & 36.79 & 37.80 & 39.05 & 2.25 \\
physicians & $\mathbf{5 4 . 5 8}$ & $\mathbf{5 2 . 8 7}$ & $\mathbf{5 1 . 7 0}$ & $\mathbf{5 0 . 4 3}$ & $\mathbf{4 9 . 7 7}$ & $\mathbf{- 4 . 8 1}$ \\
dentists & 37.82 & 38.36 & 38.19 & 39.51 & 39.08 & 1.26 \\
veterinarians & 53.34 & 49.62 & 47.93 & 48.04 & 45.58 & -7.76 \\
pharmacists & 38.95 & 38.72 & 38.19 & 38.66 & 38.61 & -0.34 \\
\hline
\end{tabular}

Source: Canadian Census from Statistics Canada. 
Table 2. The Number of Observations in the Study Sample, by Year and Gender of GP/FPs

(a) Male

\begin{tabular}{|c|c|c|c|c|c|c|c|c|c|c|}
\hline Year & Cohort 1 & Cohort 2 & Cohort 3 & Cohort 4 & Cohort 5 & Rural & Urban & Solo & Group & Total \\
\hline 1982 & 2,347 & 2,373 & 4,323 & 0 & 0 & 1,947 & 7,096 & 4,273 & 4,770 & 9,043 \\
\hline 1986 & 1,785 & 2,304 & 3,963 & 1,004 & 0 & 1,868 & 7,188 & 4,088 & 4,968 & 9,056 \\
\hline 1990 & 1,215 & 2,150 & 3,727 & 2,127 & 0 & 1,965 & 7,254 & 3,684 & 5,535 & 9,219 \\
\hline 1993 & 85 & 208 & 352 & 292 & 0 & 168 & 769 & 381 & 556 & 937 \\
\hline 1995 & 71 & 228 & 350 & 323 & 46 & 178 & 840 & 461 & 557 & 1,018 \\
\hline 1997 & 23 & 188 & 371 & 282 & 76 & 161 & 779 & 329 & 611 & 940 \\
\hline 1999 & 4 & 171 & 307 & 261 & 96 & 148 & 691 & 272 & 567 & 839 \\
\hline 2000 & 4 & 137 & 245 & 225 & 87 & 110 & 588 & 224 & 474 & 698 \\
\hline 2001 & 1 & 102 & 256 & 189 & 78 & 102 & 524 & 174 & 452 & 626 \\
\hline 2002 & 0 & 103 & 240 & 172 & 76 & 81 & 510 & 195 & 396 & 591 \\
\hline 2003 & 0 & 52 & 185 & 134 & 63 & 75 & 359 & 129 & 305 & 434 \\
\hline $\begin{array}{l}\text { Total } \\
\text { (b) Female }\end{array}$ & 5,548 & 8,180 & 14,663 & 5,277 & 614 & 6,938 & 27,344 & 14,519 & 19,763 & 34,282 \\
\hline 1982 & 230 & 327 & 1,292 & 0 & 0 & 292 & 1,557 & 667 & 1,182 & 1,849 \\
\hline 1986 & 182 & 314 & 1,178 & 573 & 0 & 338 & 1,909 & 747 & 1,500 & 2,247 \\
\hline 1990 & 150 & 342 & 1,227 & 1,397 & 0 & 435 & 2,681 & 826 & 2,290 & 3,116 \\
\hline 1993 & 7 & 43 & 109 & 203 & 0 & 40 & 322 & 119 & 243 & 362 \\
\hline 1995 & 10 & 38 & 130 & 245 & 40 & 52 & 411 & 174 & 289 & 463 \\
\hline 1997 & 6 & 37 & 122 & 250 & 73 & 60 & 428 & 112 & 376 & 488 \\
\hline 1998 & 6 & 37 & 127 & 209 & 94 & 57 & 416 & 114 & 359 & 473 \\
\hline 1999 & 2 & 26 & 108 & 236 & 116 & 60 & 428 & 91 & 397 & 488 \\
\hline 2000 & 2 & 34 & 96 & 217 & 114 & 54 & 409 & 90 & 373 & 463 \\
\hline 2001 & 0 & 23 & 108 & 172 & 120 & 61 & 362 & 61 & 362 & 423 \\
\hline 2002 & 0 & 23 & 94 & 171 & 100 & 38 & 350 & 60 & 328 & 388 \\
\hline 2003 & 0 & 20 & 74 & 147 & 79 & 35 & 285 & 57 & 263 & 320 \\
\hline Total & 595 & 1,264 & 4,665 & 3,820 & 736 & 1,522 & 9,558 & 3,118 & 7,962 & 11,080 \\
\hline
\end{tabular}


Figure 1. The Proportion of Females in the GP/FP Workforce, by Year

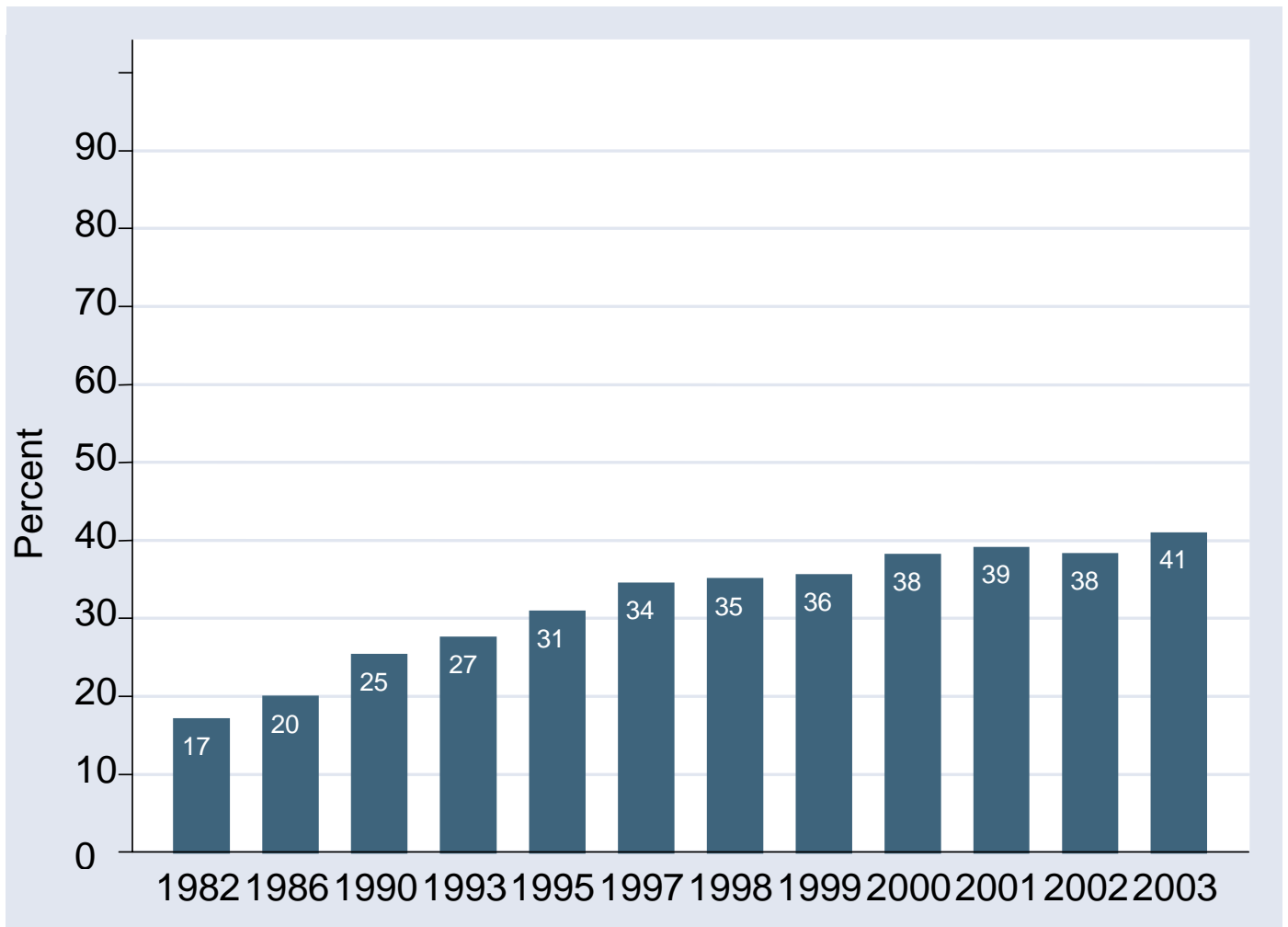


Figure 2. Average Age of GP/FPs, by year and sex

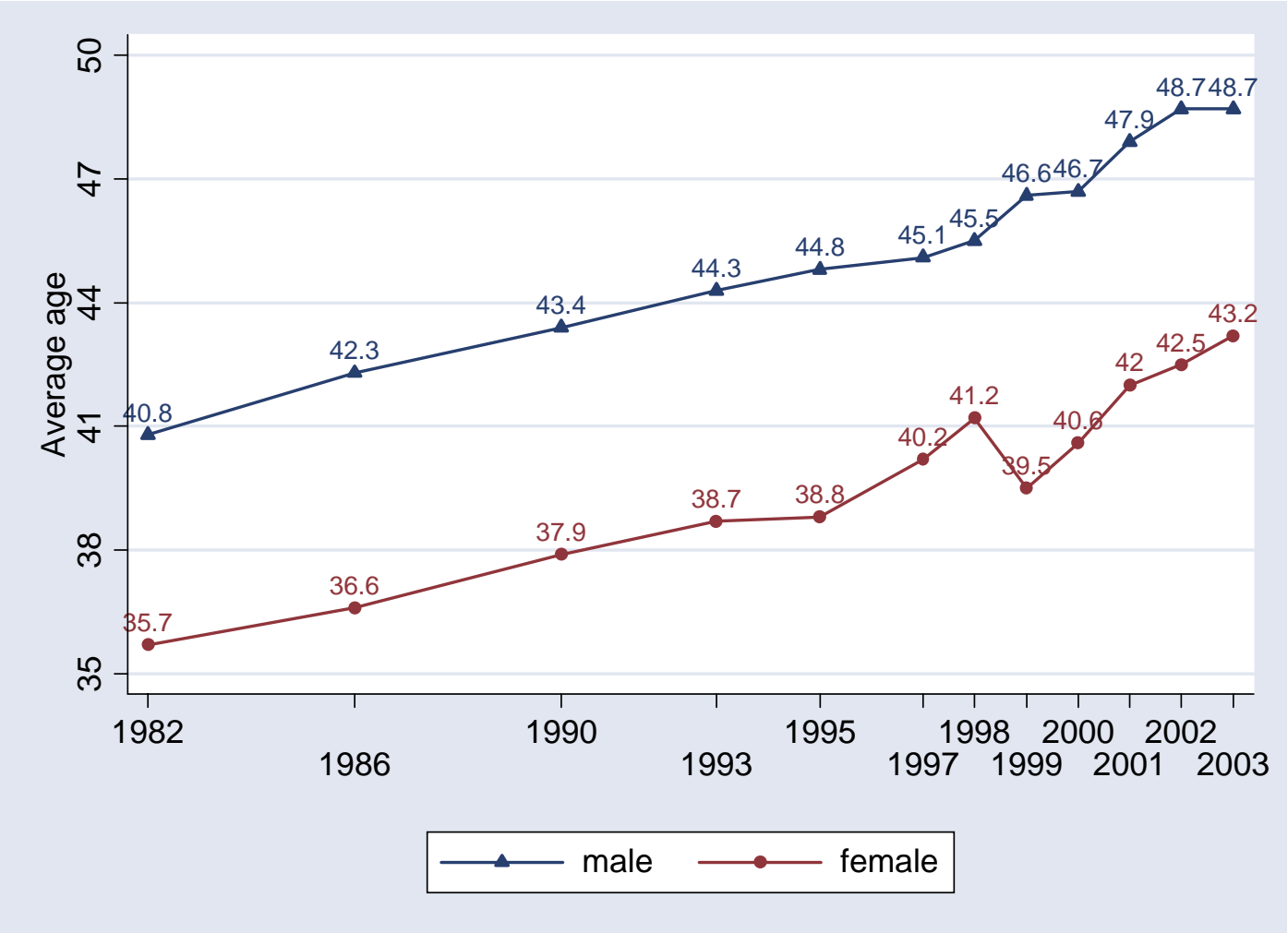


Figure 3. Cohort Analysis of Hours of Direct Patient Care, Male GP/FPs

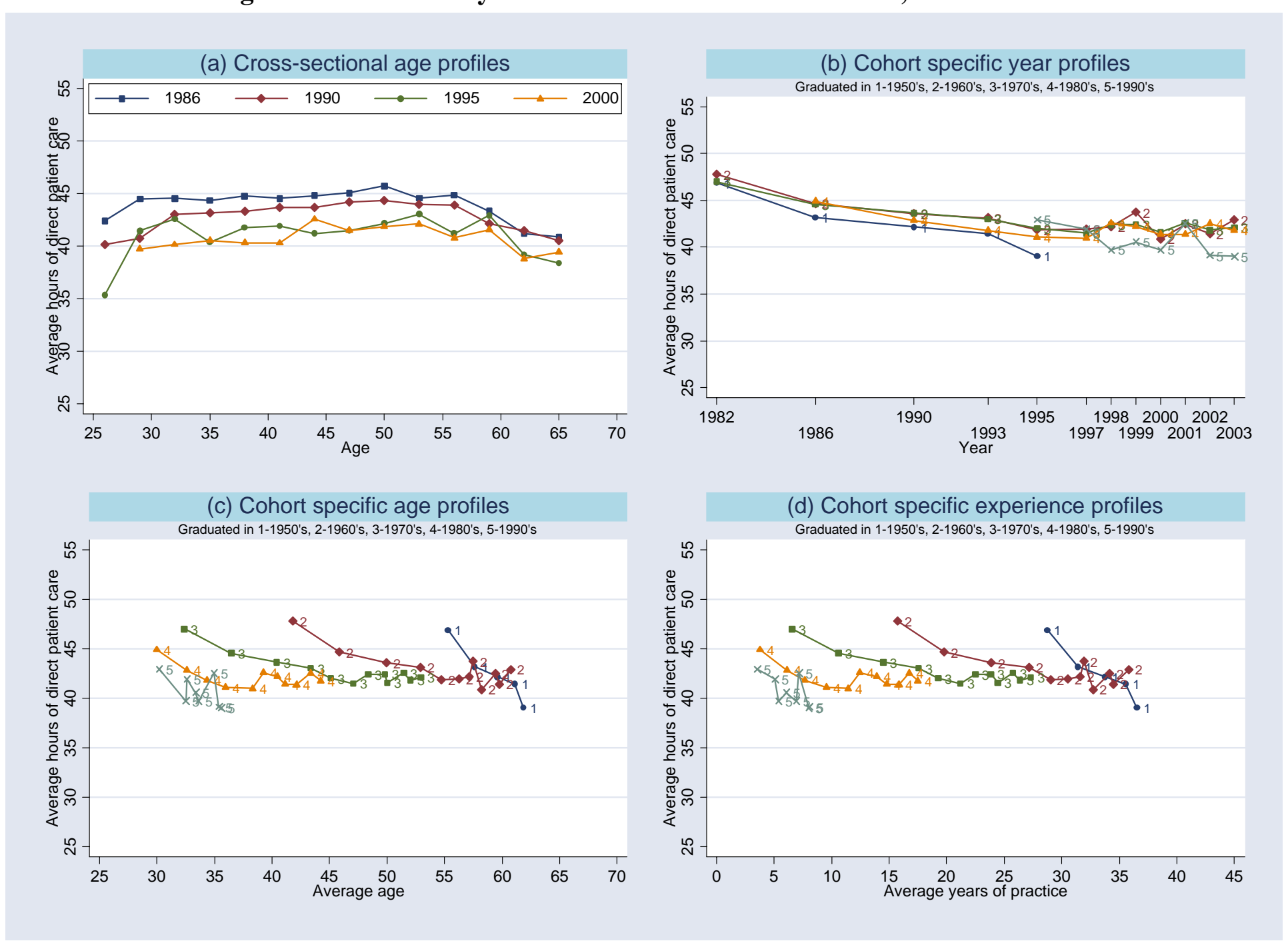


Figure 4. Cohort Analysis of Hours of Direct Patient Care, Female GP/FPs

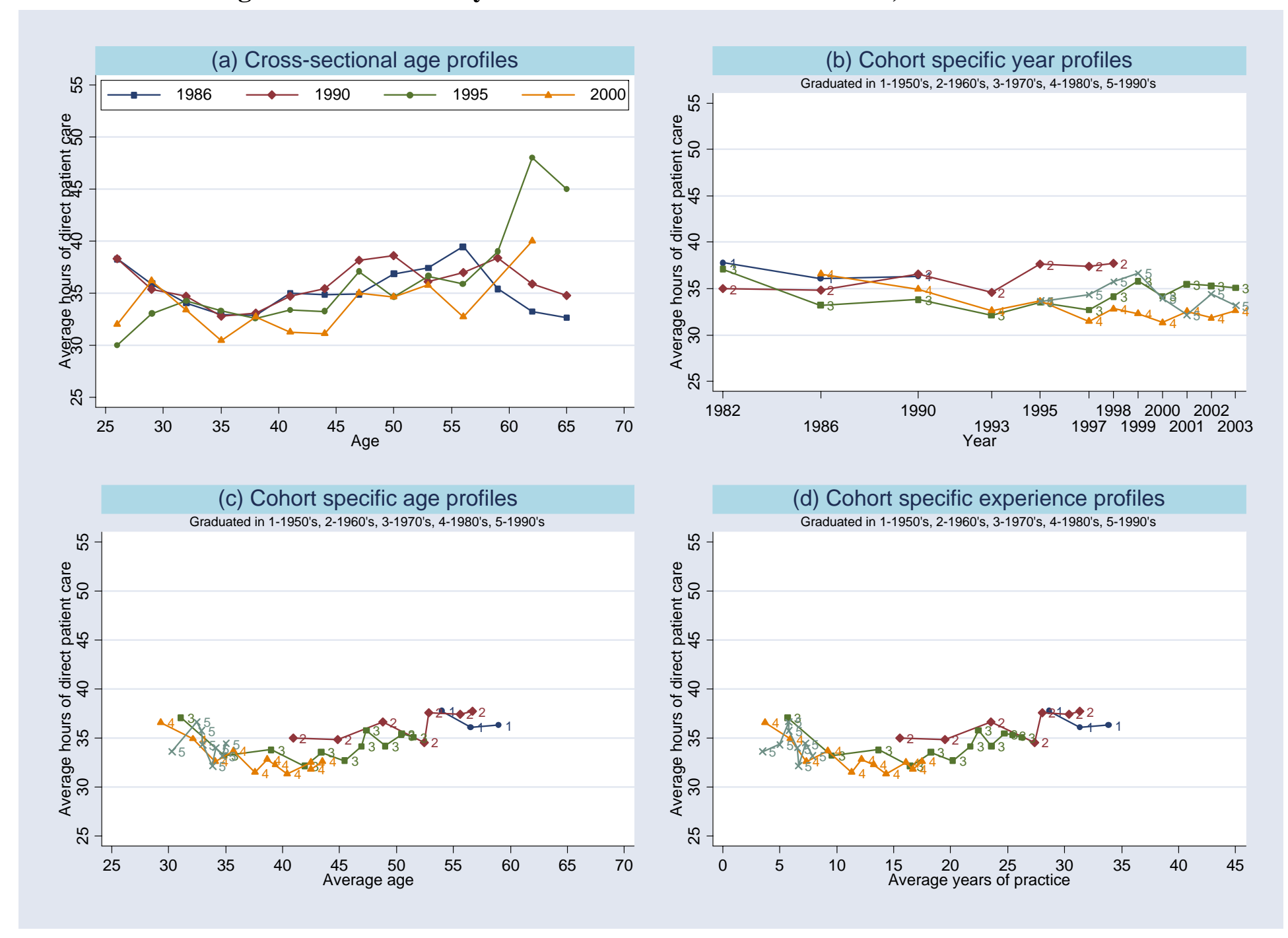


Figure 5. Total hours of work: Male GP/FPs, by Year
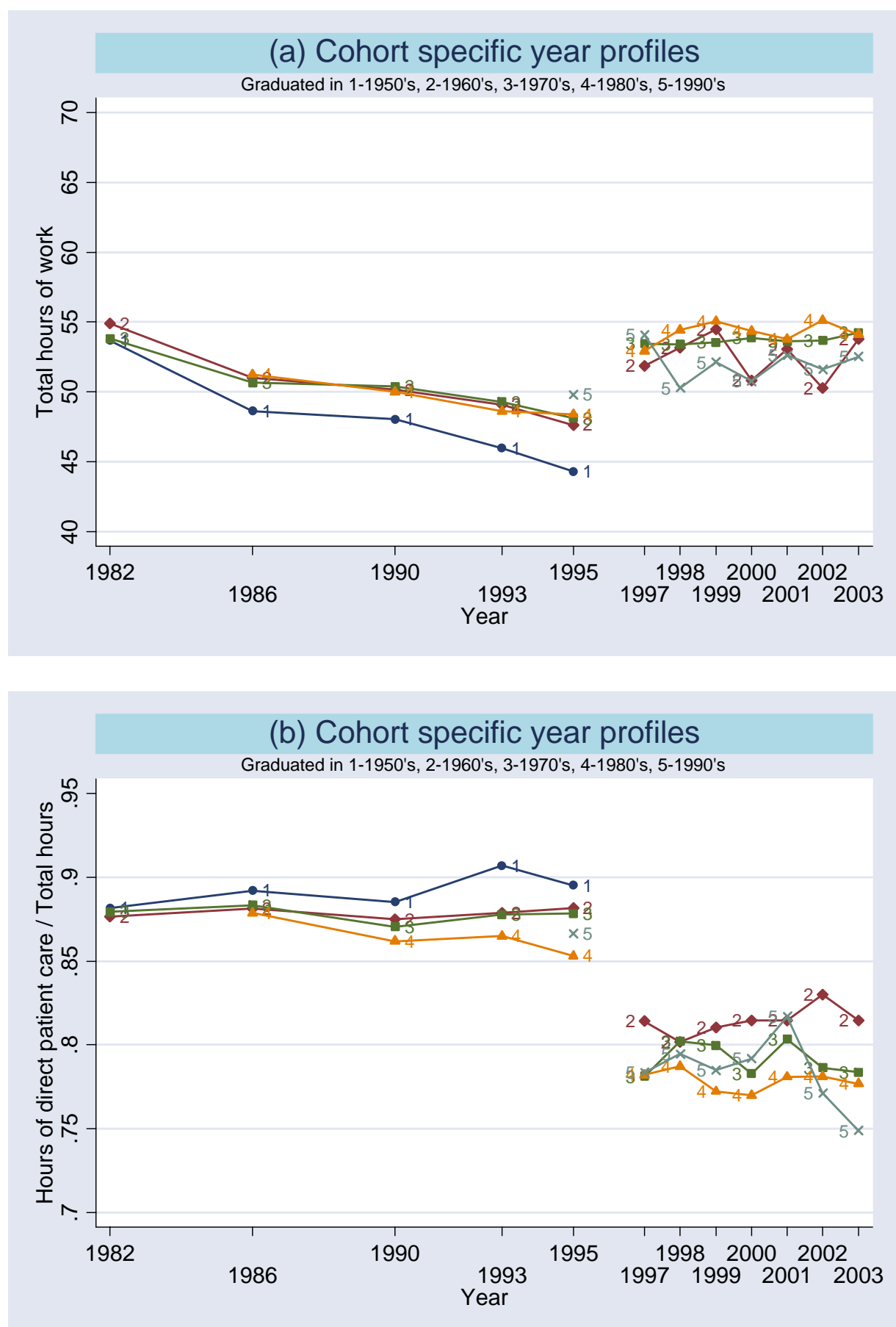
Figure 6. Total hours of work: Female GP/FPs, by Year
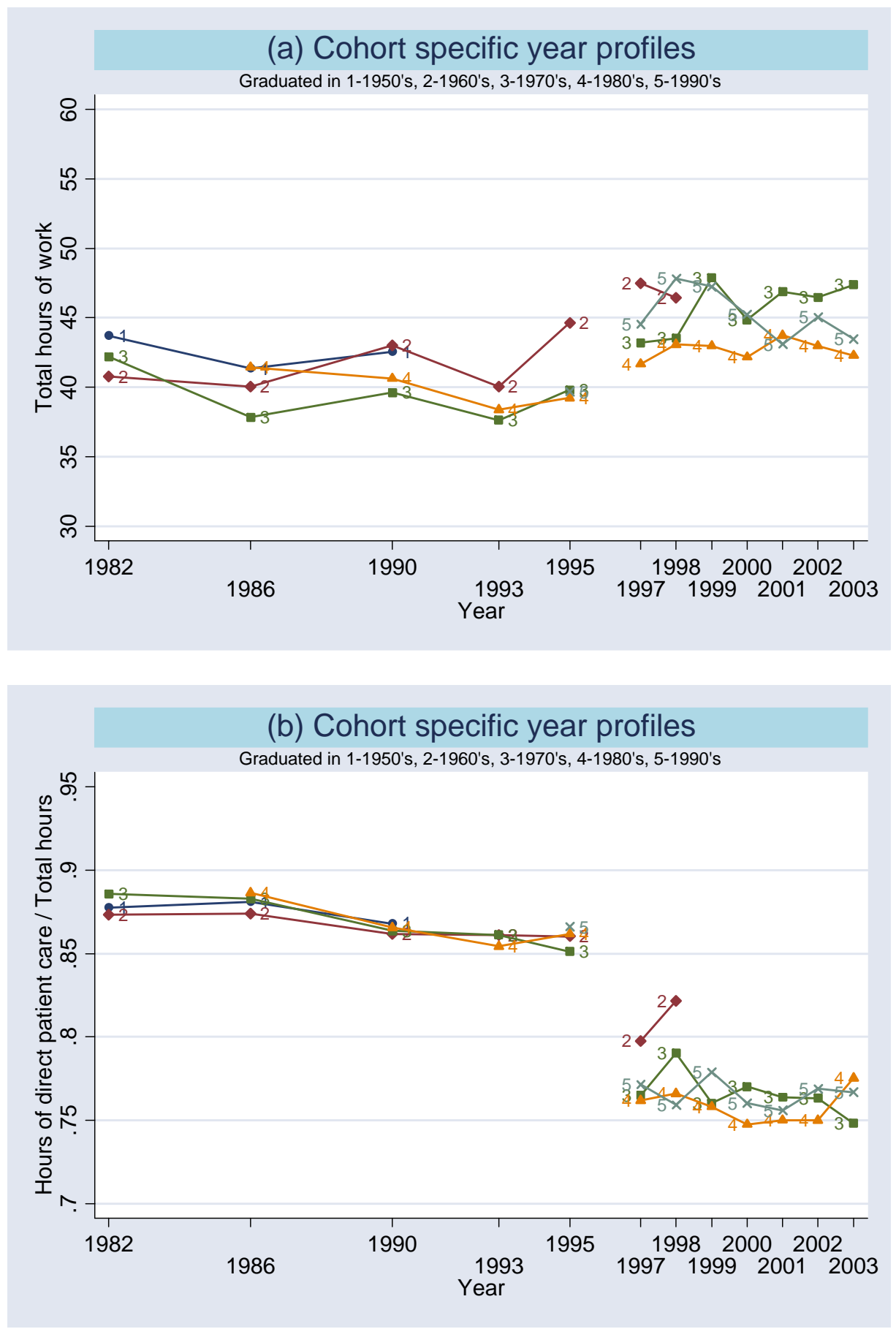
Figure 7. The Relative Impact on Average Hours of Direct Patient Care of Changed Male Labour Supply and Increasing Proportion of Females in the Physician Work Force

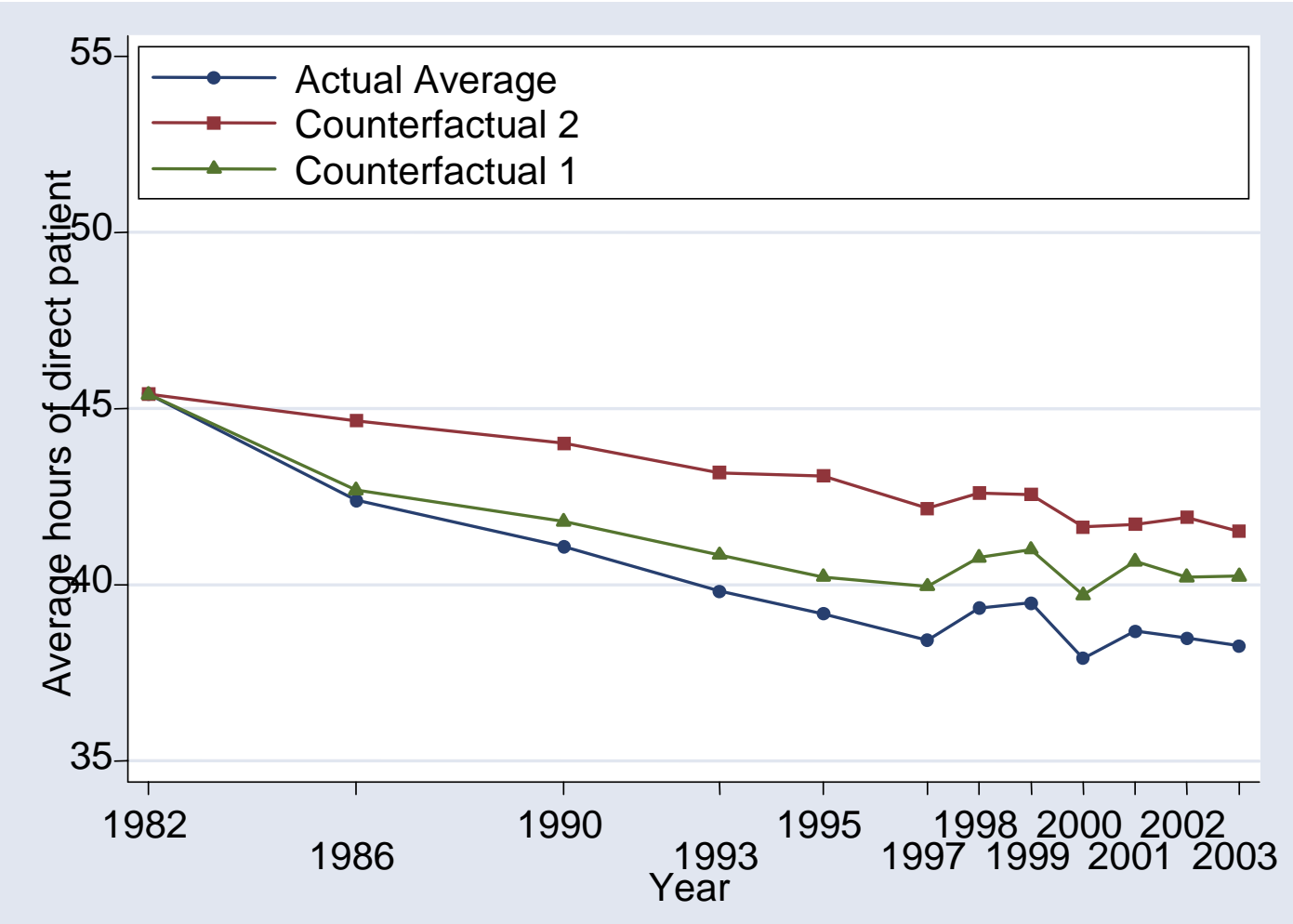

Counterfactual 1: No change in the proportion of female GP/FPs Counterfactual 2: No change in the average hours of male GP/FPs 


\section{Appendix A. CMA Survey Questions Related to working hours}

Year 2003, Excluding on-call activities, how many hours in an average week do you usually spend on the following activities?

a) Direct patient care, regardless of setting (in-patient, ambulatory and day care, non-hospital practice)

indirect patient care

b) health facility committees

c) managing your practice (staff, facility, equipment, etc.)

d) other indirect patient care (charting, reports, phone calls, meeting family, etc.)

other activities

e) research (including management of research and publications)

f) administration (management of university program, preceptorships, chief of staff, department head, Ministry of Health, etc.)

g) teaching (contact with students/residents, preparation, marking, reports, etc.)

i) other (participation in professional or specialty organizations, medico-legal activities, etc.) 


\section{Appendix B. Test of 1 - Factor Versus 2 - Factor Model, Male GP/FPs}

\begin{tabular}{|c|c|c|c|c|}
\hline \multicolumn{5}{|c|}{ Dependent Variable: hours per week of direct patient care } \\
\hline $\begin{array}{l}\text { Independent } \\
\text { Variable }\end{array}$ & Coefficient & Robust & t-statistic & Test of Joint Significance \\
\hline 1982 & 5.82 & $(0.42)$ & $13.9 * * *$ & \multirow{11}{*}{$\begin{array}{c}\mathrm{F}_{(11,21385)}=45.05 \\
\mathrm{p}<0.0001\end{array}$} \\
\hline 1986 & 2.93 & $(0.40)$ & $7.24 * * *$ & \\
\hline 1990 & 1.90 & $(0.40)$ & $4.8 * * *$ & \\
\hline 1993 & 1.36 & $(0.55)$ & $2.5 * *$ & \\
\hline 1995 & -0.14 & $(0.54)$ & -0.3 & \\
\hline 1997 & 0.66 & (0.56) & 1.2 & \\
\hline 1998 & 0.87 & $(0.56)$ & 1.6 & \\
\hline 1999 & -0.17 & $(0.60)$ & -0.3 & \\
\hline 2000 & 0.55 & $(0.60)$ & 0.9 & \\
\hline 2001 & 0.33 & $(0.62)$ & 0.5 & \\
\hline 2001 & -0.13 & $(0.74)$ & -0.2 & \\
\hline $\begin{array}{l}\text { Graduated in } \\
\text { the } 1950 \text { s }\end{array}$ & 0.0043 & $(0.28)$ & 0.02 & \multirow{5}{*}{$\begin{array}{c}\mathrm{F}_{(4,21385)}=1.07 \\
\mathrm{p}=0.3687\end{array}$} \\
\hline $\begin{array}{l}\text { Graduated in } \\
\text { the } 1970 \text { s }\end{array}$ & -0.031 & $(0.17)$ & -0.2 & \\
\hline $\begin{array}{l}\text { Graduated in } \\
\text { the } 1980 \text { s }\end{array}$ & -0.38 & $(0.30)$ & -1.3 & \\
\hline $\begin{array}{l}\text { Graduate in } \\
90 \mathrm{~s}\end{array}$ & -1.71 & $(1.00)$ & $-1.7 *$ & \\
\hline Constant & 41.92 & $(0.40)$ & $104.9 * * *$ & \\
\hline \multicolumn{5}{|c|}{ Observations: 21,401} \\
\hline \multicolumn{5}{|c|}{$\begin{array}{c}\text { Notes: } \\
<0.01 \text {; ** } \mathrm{p}<0.05 ; *\end{array}$} \\
\hline
\end{tabular}


No. 367: Alternative Pasts, Possible Futures: A "What If" Study of the Effects of Fertility on the Canadian Population and Labour Force

No. 368: Baby-Boom Aging and Average Living Standards

No. 369: The Impact of Reference Pricing of Cardiovascular Drugs on Health Care Costs and Health Outcomes: Evidence from British Columbia - Volume I: Summary

No. 370: The Impact of Reference Pricing of Cardiovascular Drugs on Health Care Costs and Health Outcomes: Evidence from British Columbia - Volume II: Technical Report

No. 371: The Impact of Reference Pricing of Cardiovascular Drugs on Health Care Costs and Health Outcomes: Evidence from British Columbia - Volume III: ACE and CCB Literature Review

No. 372: Do Drug Plans Matter? Effects of Drug Plan Eligibility on Drug Use Among the Elderly, Social Assistance Recipients and the General Population

No. 373: Student Enrolment and Faculty Recruitment in Ontario: The Double Cohort, the Baby Boom Echo, and the Aging of University Faculty

No. 374: Aggregation Effects on Price and Expenditure Elasticities in a Quadratic Almost Ideal Demand System

No. 375: Age, Retirement and Expenditure Patterns: An Econometric Study of Older Canadian Households

No. 376: Location of Adult Children as an Attraction for Black and White Elderly Return and Onward Migrants in the United States: Application of a Three-level Nested Logit Model with Census Data
F.T. Denton

C.H. Feaver

B.G. Spencer

W. Scarth

M. Souare

P.V. Grootendorst

L.R. Dolovich

A.M. Holbrooke

A.R. Levy

B.J. O'Brien

P.V. Grootendorst

L.R. Dolovich

A.M. Holbrooke

A.R. Levy

B.J. O'Brien

L.R. Dolovich

A.M. Holbrook

M. Woodruff

P. Grootendorst

M. Levine

B.G. Spencer

F.T. Denton

D.C. Mountain

F.T. Denton

D.C. Mountain

B.G. Spencer

K-L. Liaw

W.H. Frey 
No. 377: The Dynamics of Food Deprivation and Overall Health: Evidence from the Canadian National Population Health Survey

No. 378: Quebec's Lackluster Performance in Interprovincial Migration and Immigration: How, Why, and What Can Be Done?

No. 379: Out-of-Pocket Prescription Drug Expenditures and Public Prescription Drug Programs

(2003)

No. 380: Population Aging, Productivity, and Growth in Living Standards

No. 381: The Transition from Good to Poor Health: An Econometric Study of the Older Population

No. 382: The Evolution of High Incomes

In Canada, 1920-2000

No. 383: Population Change and Economic Growth: The LongTerm Outlook

No. 384: The Economic Legacy of Divorced and Separated Women in Old Age

No. 385: National Catastrophic Drug Insurance Revisited: Who Would Benefit from Senator Kirby's Recommendations?

No. 386: Wages in Canada: SCF, SLID, LFS and the Skill Premium

No. 387: Socioeconomic Influence on the Health of Older People: Estimates Based on Two Longitudinal Surveys

No. 388: An Invitation to Multivariate Analysis: An Example About the Effect of Educational Attainment on Migration Propensities in Japan
L. McLeod

M.R. Veall

K-L. Liaw

L. Xu

M. Qi

S. Alan

T.F. Crossley

P. Grootendorst

M.R. Veall

W. Scarth

N.J. Buckley

F.T. Denton

A.L. Robb

B.G. Spencer

E. Saez

M.R. Veall

F.T. Denton

B.G. Spencer

L. McDonald

A.L. Robb

T.F. Crossley

P.V. Grootendorst

M.R. Veall

A.L. Robb

L. Magee

J.B. Burbidge

N.J. Buckley

F.T. Denton

A.L. Robb

B.G. Spencer

A. Otomo

K-L. Liaw 
(2004)

No. 389: Financial Planning for Later Life: Subjective

C.L. Kemp

Understandings of Catalysts and Constraints

C.J. Rosenthal

M. Denton

No. 390: Exploring the Use of a Nonparametrically

F.T. Denton

Generated Instrumental Variable in the Estimation of a

Linear Parametric Equation

No. 391: Borrowing Constraints, the Cost of Precautionary Saving, and Unemployment Insurance

T.F. Crossley

H.W. Low

No. 392: Healthy Aging at Older Ages: Are Income and Education Important?

N.J. Buckley

F.T. Denton

A.L. Robb

B.G. Spencer

(2005)

No. 393: Where Have All The Home Care Workers Gone?

M. Denton

I.S. Zeytinoglu

S. Davies

D. Hunter

No. 394: Survey Results of the New Health Care Worker Study: Implications of Changing Employment Patterns

I.S. Zeytinoglu

M. Denton

S. Davies

A. Baumann

J. Blythe

A. Higgins

No. 395: Unexploited Connections Between Intra- and Intertemporal Allocation

T.F. Crossley H.W. Low

No. 396: Measurement Errors in Recall Food Expenditure Data

N. Ahmed

M. Brzozowski

T.F. Crossley

No. 397: The Effect of Health Changes and Long-term Health on

D.W.H. Au the Work Activity of Older Canadians

T.F. Crossley

M. Schellhorn

No. 398: Population Aging and the Macroeconomy: Explorations in

F.T. Denton the Use of Immigration as an Instrument of Control

B.G. Spencer 
No. 399: Users and Suppliers of Physician Services: A Tale of Two Populations

F.T. Denton

A. Gafni

B.G. Spencer

No. 400: MEDS-D Users’ Manual

F.T. Denton

C.H. Feaver

B.G. Spencer

No. 401: MEDS-E Users’'Manual

F.T. Denton

C.H. Feaver

B.G. Spencer

No. 402: Socioeconomic Influences on the Health of Older

N.J. Buckley

Canadians: Estimates Based on Two Longitudinal

Surveys

F.T. Denton

(Revised Version of No. 387)

A.L. Robb

B.G. Spencer

No. 403: Population Aging in Canada: Software for Exploring the

F.T. Denton

Implications for the Labour Force and the Productive

Capacity of the Economy

C.H. Feaver

B.G. Spencer

(2006)

No. 404: Joint Taxation and the Labour Supply of Married Women:

Evidence from the Canadian Tax Reform of 1988

T.F. Crossley

S.H.Jeon

No. 405: The Long-Run Cost of Job Loss as Measured by

Consumption Changes

M. Browning

T.F. Crossley

No. 406: Do the Rich Save More in Canada?

S. Alan

K. Atalay

T.F. Crossley

No. 407: The Social Cost-of-Living: Welfare Foundations and Estimation

T.F. Crossley

K. Pendakur

No. 408: The Top Shares of Older Earners in Canada

M.R. Veall

No. 409: Estimating a Collective Household Model with Survey Data on Financial Satisfaction

R. Alessie

T.F. Crossley

V.A. Hildebrand

No. 410: Physician Labour Supply in Canada: a Cohort Analysis

T.F. Crossley

J. Hurley

S.H. Jeon 